\title{
Research on Professional Identity of Flexible Employment Personnel
}

\author{
Zichen Zhang ${ }^{1}$, Ruihan Liu ${ }^{1}$ and Ge Wen ${ }^{1, *}$ \\ ${ }^{1}$ School of Management, Chengdu University of Information Technology, Chengdu, Sichuan, 610000, China \\ *Corresponding author. Email: sunlike@ cuit.edu.cn
}

\begin{abstract}
Professional identity enables employees to obtain a sense of achievement, satisfaction, dedication to work, and create high performance. Through a random survey of platform organizations in 18 cities in China, using structural equation model analysis, it is found that organizational viscosity, competency matching perception, professional expectation, professional value perception and social support have a significant positive impact on the professional identity of flexible employment personnel to varying degrees. At the same time, the five factors are also interrelated, and the optimization of any one factor can promote the improvement of other factors. On the basis of model analysis, On the basis of the correlation and promotion of the five factors, this paper puts forward some suggestions from the three levels of the country, platform organizations and individuals, such as strengthening legislation, protecting workers' rights and interests, and continuous learning, to improve the professional identity of flexible employment personnel.
\end{abstract}

Keywords: Platform organization; Professional identity; Flexible employment personnel; Structural equation

model

\section{INTRODUCTION}

Platform organization has increasingly become a new way of economic organization, and the corresponding nonstandardized flexible jobs have emerged, such as take-out, shared taxi drivers, webcast and so on. As a new employment form, flexible employment under platform organization has become a hot topic of concern from all walks of life. From the existing research point of view, most of the domestic and foreign scholars mainly focus on the reasons for the rise of flexible employment and related policy research, but ignore the research of flexible employment itself. what are the reasons for flexible employment groups to choose platform organization? What is their professional identity? What are the influencing factors? What is the relationship between these factors? These are all new problems. On the basis of previous scholars' research on flexible employment, through empirical analysis, this paper further studies the professional identity of flexible employment personnel in platform organization, which has certain theoretical and practical significance for the development of platform organization and the in-depth study of flexible employment population.

\section{RESEARCH DESIGN}

\subsection{Research Hypothesis and Model Building}

Professional identity refers to the individual's positive evaluation of the occupation [1]. He Shuangshuang in the study of professional identity pointed out that organizational support positively affects professional identity [2]. However, the interaction between organizations and employees is not limited to organizational support, and there is some stickiness between platform organizations and flexible employees. Therefore, the first dimension of flexible employment professional identity is organizational viscosity, Meanwhile, proposing the following hypothesis.

$\mathrm{H} 1$ : Organizational viscosity of the platform organization has a positive influence on the professional identity of flexible employment personnel.

Pratt and his partners point out that when people find that they do not match their profession, their professional identity changes [3]. Therefore, the second dimension of professional identity is selected, competency matching perception, and the following hypothesis is proposed.

H2: Flexible employment personnel's competency matching perception in platform organization has the positive influence to their professional identity.

Wang Xinqiang and his partners pointed out that professional expectations have a positive impact on 
professional identity [4]. The future development of flexible employment has huge potentials to develop, understanding the professional expectations of flexible employment personnel will help to better grasp their professional identity. Therefore, the third dimension of flexible employment is professional expectation, and the following hypothesis is proposed.

H3: Flexible employment personnel's professional expectation in platform organization has positive influence to their professional identity.

Sun $\mathrm{Li}$ pointed out that professional value will have a positive impact on individual professional identity [5]. The individual's professional value is the value measure of the individual's inner perception, so the professional value perception is proposed as the fourth dimension of the flexible employment personnel's professional identity, and the following hypothesis is proposed.

H4: Professional value perception of flexible employment personnel in platform organization will have a positive influence on their professional identity.

Flexible employment and social support have al-ways been a hot topic of discussion, Liu Ling and her partners put forward that social support will have an impact on professional identity [6]. Therefore, social support is regarded as the fifth dimension of the professional identity of flexible employment personnel, and the following hypothesis is proposed.

H5: Social support of flexible employment personnel in platform organization has a positive influence on their professional identity.

Organizations with high viscosity provide support to employees to improve their competency matching perception. Professional expectation is an active pursuit of employees, So they coordinate their ability with their professional requirements. It can be seen that the perception of competency matching will have an impact on professional expectations. In addition, Yang Xuhua pointed out that professional value will also have a certain impact on professional expectations [7]. Du Tian found that social support has a positive effect on professional value [8]. Therefore, the following four hypotheses are proposed.

H6: Organizations viscosity has a positive influence on functional matching perception.

H7: Competency matching perception has a positive influence on professional expectations.

H8: Professional value perception has a positive influence on professional expectations.

H9: Social support has a positive influence on professional value perception.

To sum up, the conceptual model of flexible employment about professional identity is established (Figure 1).

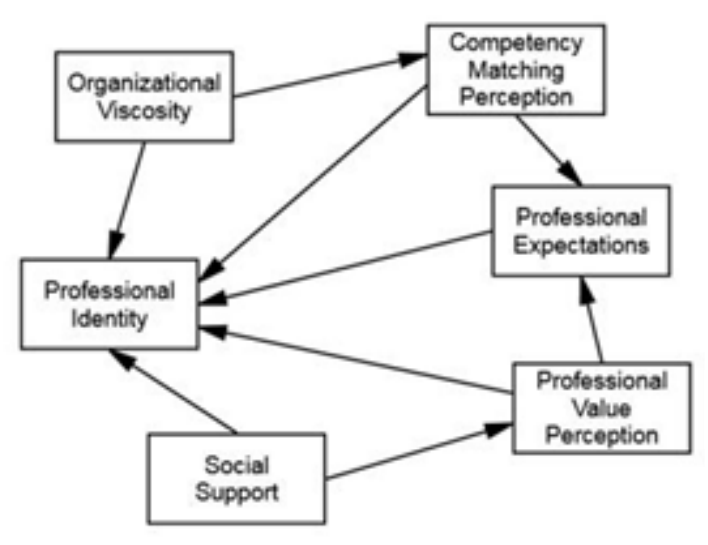

Figure 1. Conceptual model of professional identity for flexible employment.

\subsection{Variable description}

The organizational viscosity questionnaire was developed by Zhou Hong, selecting growth development requirements, emotional demands and stable development intentions as organizational viscosity items [9]. The competency matching perception is based on the three factors that Parsons founded the theory of "job matching ": self-cognition, cognitive occupation and thinking about the first two factors to achieve job matching [10]. Professional expectation scale was developed by Wang Xinqiang and his partners, which mainly included items such as professional will, professional expectation [4] Professional value perception scale was developed by Wei Shuhua and her partners [11]. Social support scale adopts the social support rating scale developed by Xiao Shuiyuan, which includes objective support, subjective support and other items. Objective sup-port refers to visible or actual support, and subjective support refers to experienced emotional support. Zou Jiying pointed out that there is space for development and pay for professional identity [12]. According to Maslow's hierarchy of needs theory, lower levels of needs can be met by matter, while higher levels of needs cannot be met by matter. On this basis, the development space, salary level, whether respected as the measure variables of professional identity. There are 40 questions in the questionnaire, which are mainly divided into two parts: the first part is the basic information of the respondents, including age, sex, education, marital status and other basic information; the second part is the measurement of professional identity.

\section{DATA COLLECTION}

In this paper, a random questionnaire survey of flexible employment personnel organized by 18 urban platforms, Mainly through online and field surveys, A total of 463 questionnaires were collected, Excluding 11 invalid questionnaires, Total 452 valid questionnaires recovered, 
The effective recovery rate is approximately $97.6 \%$, The basic information of the sample is as follows: $78.3 \%$ married, $21.7 \%$ un-married; $60.8 \%$ men, $39.2 \%$ women; $51.8 \%$ aged $20-35,31.4 \%$ aged $36-50,12.4 \%$ aged 20 or under, $4.4 \%$ over 50 years of age; $3.1 \%$ bachelor degree or above, $17.5 \%$ undergraduate, $38.7 \%$ junior college, high school accounts for $30.3 \%$, junior high school and below account for $10.45 \%$

\section{RESULTS}

Reliability analysis. SPSS software was used to analyse the reliability of the questionnaire, Cronbach's $\alpha$ coefficient of the questionnaire was 0.924 , and Cronbach's $\alpha$ coefficients of scales were $0.854,0.850,0.856,0.845$,
0.853 and 0.865 , More than 0.8 , So it can be seen that the questionnaire has good re-liability.

Validity analysis. KMO values were $0.913,0.913,0.905,0.872,0.861$ and 0.736 , respectively, indicating that scales had good measurement validity.

Model fitting analysis. By using the AMOS21.0 to draw the structural equation model of the influencing factors of the professional identity of the flexible employment personnel in the platform, the five latent variables of organizational viscosity, competency matching perception, professional expectation, professional value perception and social support were observed to directly affect the professional identity of the flexible employment personnel in the platform organization, as well as the interaction between them. The normalized path coefficient obtained from the operation is shown in Figure 2.

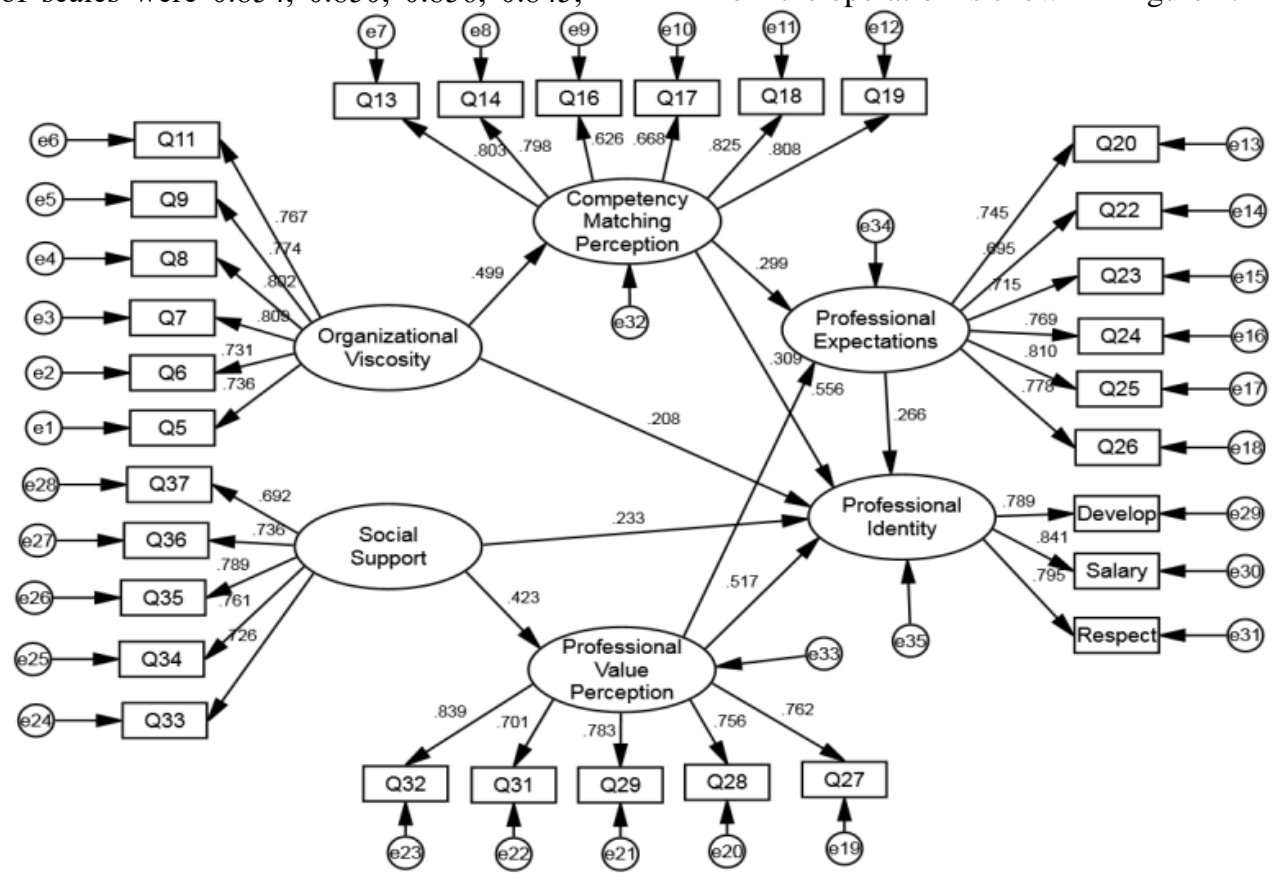

Figure 2. Standardized Estimation of Structural Equation Model .

The structural equation model hypothesis test results of professional identity are shown in Table 1, where S.E. represent standardized error, C.R. represent t value ,"*" represents significant level of path coefficient less than
0.001 , usually $\mathrm{P}$ value less than 0.05 indicates that the original hypothesis can be accepted. Otherwise, reject the original hypothesis.

Table 1. Experimental results of the hypothesis test of the structural equation model

\begin{tabular}{cccccc}
\hline Hypothesis & $\begin{array}{c}\text { Standardized } \\
\text { coefficient }\end{array}$ & S.E & C.R & $\begin{array}{c}\text { Signifi } \\
\text { cance }\end{array}$ & Result \\
\hline H1 & 0.208 & 0.049 & 6.181 & $* * *$ & True \\
H2 & 0.309 & 0.041 & 8.289 & $* * *$ & True \\
H3 & 0.266 & 0.073 & 6.614 & $* * *$ & True \\
H4 & 0.517 & 0.061 & 11.473 & $* * *$ & True \\
H5 & 0.233 & 0.060 & 6.886 & $* * *$ & True \\
H6 & 0.499 & 0.072 & 9.340 & $* * *$ & True \\
H7 & 0.299 & 0.028 & 6.443 & $* * *$ & True \\
H8 & 0.556 & 0.039 & 10.636 & $* * *$ & True \\
H9 & 0.423 & 0.071 & 7.706 & $* * *$ & True \\
\hline
\end{tabular}

Note :"***" means $\mathrm{p}<0.001$ 


\section{DISCUSSION}

Table 1 and Figure 2 show that organizational viscosity has a significant positive influence on the professional identity of flexible employees in the platform organization, that is, the better the organizational viscosity of platform organizations, the higher the career identity of flexible employees, so H1 hypothesis holds; competency matching perception has a very significant positive influence on professional identity, that is, the better the competency matching perception of flexible employees, The higher career identity, so $\mathrm{H} 2$ hypothesis holds; professional expectation has a significant positive impact on professional identity, that is, the higher professional expectation is, the higher career identity is, so $\mathrm{H} 3$ hypothesis holds; professional value perception has a significant positive influence on professional identity, that is, the higher professional value perception is, The higher professional identity is, so $\mathrm{H} 4$ hypothesis holds; social support has a significant positive influence on professional identity, that is, the higher social support that flexible employment personnel receive, the higher professional identity is, so $\mathrm{H} 5$ hypothesis holds.

According to Figure 2, among the five variables, the perception of professional value and competency matching perception have the greatest influence on professional identity, while the organizational viscosity has the smallest influence. This is more or less related to the current insufficient attention to the flexible employment personnel, causing the flexible employment personnel turn to pay more attention to the overall situation of themselves and the profession itself. For the observation index of professional identity, the biggest influence is the level of salary, followed by the degree of respect, and finally the development space. According to Maslow's demand theory, people's work is the first pursuit of survival needs, and salary is the premise to meet the survival needs. After the low-level needs are met, there will be higher-level needs, such as the needs of respect and self-realization.

At the same time, it is found that organizational viscosity will directly have a significant positive influence on the competency matching perception of flexible employment personnel, and competency matching perception of flexible employment personnel will directly have a significant positive influence on their professional expectations; social support will directly have a significant positive influence on the perception of professional value of flexible employment personnel. Therefore, H6, H7, H8 and $\mathrm{H} 9$ four assumptions hold. It is not difficult to see that these five variables do not exist in isolation, but are interrelated. The improvement of any one factor can promote the improvement of other factors. Therefore, in order to enhance the career recognition of flexible employment personnel in platform organization, we should comprehensively consider the relationship between the five factors.

\section{CONCLUSION}

This paper makes an in-depth study on the influencing factors of the professional identity of the flexible employment personnel in the platform organization, and finds that organizational viscosity, competency matching perception, professional expectation, professional value perception and social support have a positive influence on professional identity of the flexible employment personnel, and these five aspects are related, So putting forward the following suggestions.

At the level of national, establishing and improving flexible employment related systems. We should constantly improve relevant laws and regulations, such as how to define the labour relationship between platform organizations and flexible employment personnel, formulate preferential policies conducive to supporting flexible employment, and increase publicity efforts to ensure that flexible employment personnel understand the policy. Relevant departments should also pay attention to strengthening supervision to ensure the implementation of the policy.

At the level of platform organization, while developing also avoiding employment risk. The plat-form organization should not only abide by the relevant regulations of the state on flexible employment policies and systems, but also take the initiative to protect the rights and interests of flexible employment personnel. Providing training for flexible employment personnel at random to improve their vocational skills and employability; developing a scientific and reasonable salary system for flexible employment personnel to ensure their income is guaranteed. Do not ignore flexible employment personnel, taking the initiative to care of them, giving guidance to work, finding problems or employees in urgent need of help, timely helping and caring.

At the level of flexible employment personnel, professional literacy should be promoted. First of all, flexible employment personnel should cultivate professionalism. secondly, they should have the ability to learn, constantly learn, improve their own professional skills, and enhance their professional competence. they should also learn professional planning and clarify their professional goals. Grasping the direction of their professional development.

\section{REFERENCES}

[1] Qi Zhe. Professional identity and burnout [J]. Professional Space, 2005, (08):1. (In Chinese). DOI: 10.3969/j.issn.1672-8963.2005.04.001.

[2]He Shuangshuang, Tang Jing. Effect of Organizational Support Sense on Professional Identity [J]. of Medical Personnel China Medical Guide, 2015, 12(06):145-149. (In Chinese). DOI: CNKI:SUN:YYCY.0.2015-06-039 
[3]Pratt M G, Rockmann K W, Kaufmann J B. Constructing Professional Identity: The Role of Work and Identity Learning Cycles in the Customization of Identity among Medical Residents [J]. The Academy of Management Journal, 2006, 49(2): 235-262. DOI: $10.2307 / 20159762$

[4]Wang Xinqiang, Zeng Lihong, Zhang Dajun, et al. A preliminary compilation of the Professional Identity Scale for Normal Students [J]. Journal of Southwest University (Social Sciences Edition), 2010, 36(05):152157. (In Chinese). DOI: 10.3969/j.issn.16739841.2010.05.033

[5]Sun Li, Zou Bin. Construction and Measurement of Professional Identity of Primary and Secondary School Teachers [J]. Educational Research and Experiments, 2010, (05):80-84. (In Chinese). DOI:

CNKI:SUN:YJSY.0.2010-05-018

[6]Liu Ling, Hao Yufang, Liu Xiaohong. Development of Nurses' Professional Identity Scale [J]. PLA Nursing Journal, 2011, 28(03):18-20. (In Chinese). DOI: 10.3969/j.issn.1008-9993.2011.03.006

[7]Yang Xuhua, Yang Rui. Structure and Analysis of Professional Social Workers' Professional Identity Taking Beijing as an Example [J]. Journal of Beijing University of Aeronautics and Astronautics (Social Sciences Edition), 2014, 27(06):15-20. (In Chinese). DOI: CNKI:SUN:BHDS.0.2014-06-004
[8]Du Tian, Feng Wei. A Study on the Value Orientation of Free Normal Students in Choosing Teacher's Occupation [J]. Journal of Sichuan Institute of Education, 2011, 27(04):23-27. (In Chinese). DOI: 10.3969/j.issn.1000-5757.2011.04.023

[9]Zhou Hong. Reflections on the Promotion of viscosity of Young Technical Talent Organization in Geological Prospecting Units - Taking 208 Geological Teams of Chongqing Geological Prospecting Bureau as an example [J]. China Management Informatization. 2018, 21(23):111-114. (In Chinese). DOI: CNKI:SUN:GLXZ.0.2018-23-048

[10]Chen Xiaoyi, Liu Chenggang, Wang Lin, et al. A Study on Employment Quality Tracking of Graduates Based on Job Matching Theory [J]. Private Science and Technology, 2015, (01):260. (In Chinese). DOI: 10.3969/j.issn.1673-4033.2015.01.247

[11]Wei Shuhua, Song Guangwen, Zhang Dajun. A Structure and Scale of Professional Identity of Primary and Secondary School Teachers in China [J]. Research on Teacher and Education, 2013, 25(01):55-60+75. (In Chinese). DOI:CNKI:SUN:GDSZ.0.2013-01-010

[12] Zou Jiying, Wang Peng, Chen Zhijuan. A Study on the Influencing Factors of College Counselors' Professional Identity Based on Structural Equation Model [J]. Journal of the National Institute of Education Administration, 2014, (09):15-20. (In Chinese). DOI: 10.3969/j.issn.1672-4038.2014.09.003 